\title{
RESENHA DE MACHADO DE ASSIS E O CÂNONE OCIDENTAL: ITINERÁRIOS DE LEITURA, DE SONIA NETTO SALOMÃO
}

\section{REVIEW OF MACHADO DE ASSIS E O CÂNONE OCIDENTAL: ITINERÁRIOS DE LEITURA, BY SONIA NETTO SALOMÃO}

SALOMÃO, Sonia Netto. Machado de Assis e o cânone ocidental: itinerários de leitura. Rio de Janeiro: Eduerj, 2016. 432 p.

\section{MARCOS FALCHERO FALLEIROS}

Universidade Federal do Rio Grande do Norte Natal, Rio Grande do Norte, Brasil

$\mathrm{U}$ ma arqueologia de Machado de Assis: assim pode ser classificado o estudo de Sonia Netto Salomão, professora titular de língua e tradução portuguesa e brasileira na Sapienza - Università di Roma. A origem ajuda a explicar seu minucioso trabalho de pesquisa sobre os vínculos de Machado com a cultura italiana. Entretanto, embora seja esse o fio condutor da obra, a autora se desobriga de frisar no título de seu livro o foco na Itália, como a provar de saída que sua abordagem não se limita a um aspecto episódico ou pitoresco do escritor brasileiro. Pelo contrário, os resultados que apresenta apanham Machado de Assis na totalidade de sua grandeza. Daí a dupla intenção que sua atitude crítica deixa transparecer no aviso machadianamente lacunar do título: por um lado, afirma que seu objeto é o Machado inteiriço, por outro, comprova, afinal, nessa completude, a decisiva influência da cultura italiana em sua literatura.

$\mathrm{O}$ vasto sítio arqueológico de Machado, sempre vivo, em que se sedimentam não só camadas da própria obra como também descobertas e esquecimentos, acolhe igualmente imensa bibliografia, raiz e seiva de uma fortuna crítica que vai se acamando no correr destes últimos séculos, muitas vezes silenciada pelas novas abordagens. Diante dessas novidades, o estudante de Machado posicionado na superfície ficará limitado a vagas 
notícias do lastro antecedente, quando fornecidas por informações ralas de alguma eventual nota de rodapé.

Contra a corrente dessa tendência, a autora opera profundas prospecções, em três frentes: nas relações de influência sobre o Machado leitor, nos sucessivos estratos interligados de sua recepção pela crítica, nas teorizações que fundamentam as escolhas de itinerário do estudo. O trabalho didático de lançadeira tece com fluidez um desenho claro, com o objetivo de trazer à tona o escritor carioca situado no cânone ocidental, não sem antes discutir os aspectos teóricos do conceito e lembrar outros vínculos, como a cultura africana e a oriental. O desenho situa o mestre da periferia do capitalismo: estando no terreno da cultura brasileira, ele incorporou dialeticamente o cânone como leitor refinado que burilou sua formação pelas altas tradições da cultura ocidental. Conforme sublinha a pesquisadora, exerceu papel de destaque nesse processo formativo, e não só nos momentos da densa atividade teatral de juventude, a dinâmica empresarial sistemática dos espetáculos de ópera italiana, que, num frenesi de torcidas por artistas, com a participação de Machadinho, ocupou fartamente o espírito do tempo na capital do Império, quem sabe - pode-se conjecturar apesar da escassez de dados - sob o acolhimento de uma princesa napolitana nos seus 46 anos de reinado ao lado de d. Pedro II.

Assim, o conceito de hipertexto, banalizado como link pelo senso comum da terminologia de informática, retorna ao refinamento que ultrapassa a noção de mera intertextualidade para instrumentalizar o restauro do palimpsesto machadiano. O processo é contextualizado pela exposição reflexiva, que, sem esquecer as contribuições italianas, apresenta as linhas e procedimentos no percurso teórico de Saussure, Bakhtin, Barthes, Kristeva, Genette, Jakobson, Ricoeur, Harold Bloom, entre outros lembrando inclusive, num atilado aceno ao leitor surpreso, o conceito de figura que Auerbach equacionou em sua leitura de Dante -, para finalmente concluir o silogismo das modulações simbólicas e das referências cruzadas com a formulação, à Oswald, de uma antropofagia ante litteram em Machado. Também aí é com cuidadoso viés interpretativo da obra de Oswald que a simpática formulação se mostra bem acima da mera tirada expressiva, considerando a respeito proposições de Benedito Nunes e de Roberto Schwarz.

Nesse diapasão, o andamento da obra se ritma abarcando exaustivamente a copiosa bibliografia de Machado de Assis e correlatos, sempre atenta para não deixar escapar de sua visada crítica aspectos 
admiráveis como os do "cânone contra cânone", num aporte interpretativo em que se contrapõem duas obras tão díspares, de publicação coetânea, como Quincas Borba e $O$ cortiço.

As pontas do novelo italiano, cujo desenrolar efetivo ocupará metade de seu volume de estudo no terceiro e conclusivo capítulo, vão sendo indicadas profusamente no transcorrer das análises precedentes, com uma prodigalidade, difícil de resumir, de achados, pormenores em pontos instigantes e quadros comparativos. Para dizer mais no espaço apertado de uma resenha, o exemplo da passagem seguinte pode ser suficiente: ao caracterizar a amalgamação multifacetada das fontes do escritor com discutir a gênese do delírio de Brás Cubas, através das variadas versões que o aparato crítico vem apresentando há tempos, em determinado momento a autora historia a discussão conhecida entre os especialistas relativa às influências na construção do nuclear capítulo VII de Memórias póstumas, quando Augusto Meyer deu importância a Tentation de Saint Antoine de Flaubert, contrapondo-a à indicação de Eugênio Gomes, de La légende des siècles de Victor Hugo. A operação hermenêutica, a partir da intervenção de Carpeaux, incorporou de Leopardi, das Operette Morali, o "Dialogo della Natura e di un Islandese". Daí a autora parte para abordagens posteriores, como as de José Guilherme Merquior e de Enylton de Sá Rego, vai às contemporâneas e volta aos topoi de Ernst Robert Curtius para encontrar seu processo teórico fraterno ao de um Machado crítico e consciente de seu fazer literário, tal qual professado pelo escritor carioca na "Advertência" a seu poema paródico, OAlmada, que é apresentado com as devidas contextualizações de sua publicação e de seus modelos.

"Teoria da chapa", "teoria do molho", "teoria do falsete" são as formulações reelaboradas e ampliadas, oriundas de passagens, comentários e insinuações do autor nos seus jogos de citação e máscara. São evocadas para lembrar, e lembradas para lembrar que Machado, portanto, não construiu intuitivamente sua literatura, mas antes como teórico e crítico que filtrou e adaptou sua erudição com fina sagacidade. Sua ironia, numa obra com a força de $O$ alienista, por exemplo, conduz, subjacente ao enredo, um piscar de olhos ao riso de Demócrito, em suas implicações com Sobre o riso e a loucura de Hipócrates (pseudo), e às lágrimas de Heráclito: sabedoria, loucura, melancolia, misantropia, niilismo.

A pesquisadora se entrega, no vigoroso terceiro capítulo, a um percurso que certamente agradaria a quem, na juventude, exprimiu em versos não só sua paixão pelas divas da ópera como também pela Itália. Um Machado que, 
nel mezzo del cammin di nostra vita, tornou-se em 1874, com o Canto XXV do Inferno, um dos tradutores pioneiros de Dante no Brasil; e que, na maturidade, como aparece na epígrafe do capítulo, confessava em correspondência pelos idos de 1896 ao amigo diplomata de Roma, Magalhães de Azeredo: "A Itália dá-me não sei que reminiscências clássicas e românticas, que faz crescer o pesar de não haver pisado esse solo tão amassado de história e de poesia". Indícios como esses são corroborados pelo extenso tratado que o capítulo engendra, cujo roteiro, repleto de correlações surpreendentes, acompanha: a viagem à Itália através de Stendhal, como deixam ver as pistas das leituras de Machado conservadas em sua biblioteca na Academia Brasileira de Letras, a etimologia histórica de Capitu, a perscrutação dos medalhões dos imperadores romanos e do aliado pintados na casa de Dom Casmurro em Matacavalos e na réplica frustra do Engenho Novo, o grande afluxo da corrente migratória italiana ao Rio de Janeiro e o frenesi das óperas, que justifica a detalhada configuração do Bentinho-Otelo, menos devedora de Shakespeare que de suas adaptações operísticas, especialmente a de Verdi (ao contrário do que pensou Helen Caldwell).

Encerra-se o livro com o foco detido na recepção da obra de Machado de Assis na Itália, em que as questões de teorias da tradução são discutidas na compilação comparativa, exigente e ponderada, das traduções publicadas naquele país, ainda insuficientes, frente à importância do autor para a literatura ocidental.

O evento e a forma são os termos do binômio com que, em sua coletânea de ensaios Céu, inferno, Alfredo Bosi, absorvendo a formulação do filósofo italiano Carlo Diano, apontou para a complexidade da interpretação literária, substituindo com aquela correlação mais densa de sentido a simplificada expressão tradicional forma e conteúdo. ${ }^{1}$ Posteriormente, com Brás Cubas em três versões, retomando suas Reflexões sobre a arte, o crítico lembrou as três vias de conformação da obra artística: construção, expressão e conhecimento ${ }^{2}$ - para requerer uma leitura que não imponha a monocausalidade que sobredetermine sua interpretação. ${ }^{3}$

A condução que Sonia Netto Salomão dá a seu trabalho atesta uma pesquisadora alinhada a essas proposições, atenta tanto ao "evento", que impregna as operações textuais com a temporalidade e a subjetividade do escritor, ${ }^{4}$ quanto à não exclusão de linhas interpretativas, como comprova o

${ }^{1}$ Cf. BOSI, A interpretação da obra literária, p. 463.

${ }^{2}$ Cf. BOSI, Reflexões sobre a arte, p. 8.

${ }^{3}$ Cf. BOSI, Brás Cubas em três versões, p. 38 e 51.

${ }^{4}$ Cf. BOSI, A interpretação da obra literária, p. 463. 
desdobramento de suas interpretações ao acatar e discutir abertamente pontos pertinentes aos seus nas leituras que a precederam. Além de reverenciar abrangentemente a tradição crítica e o trabalho apurado dos pesquisadores contemporâneos, fartamente aproveitados, as peças arqueológicas apresentadas em sua multiplicidade fragmentária indiciam o quebra-cabeça do Machado inteiriço, e fazem ver ao leitor incauto, depois de ter passado distraidamente pelo subtítulo "itinerários de leitura", que sua arqueologia conduz a uma longa viagem pelo oceano machadiano, inesgotável e profundo.

\section{Referências}

BOSI, Alfredo. A interpretação da obra literária. In: Céu, inferno: ensaios de crítica literária e ideológica. São Paulo: Duas Cidades; Ed. 34, 2003, p. 461-479.

.Brás Cubas em três versões: estudos machadianos. São Paulo: Companhia das Letras, 2006.

. Reflexões sobre a arte. São Paulo: Ática, 2003 (Fundamentos, 8).

MARCOS FALCHERO FALLEIROS é professor da Universidade Federal do Rio Grande do Norte, UFRN. E-mail: marcffal@gmail.com. 